\title{
Effect of Chlorpyrifos Ethyl on Acetylcholinesterase Activity in Climbing Perch (Anabas testudineus, Bloch, 1972)
}

\author{
Nguyen Thanh Tam ${ }^{1,3}$ (1) Håkan Berg ${ }^{3} \cdot$ Phan Thi Bich Tuyen ${ }^{2} \cdot$ Nguyen Van Cong $^{2}$
}

Received: 1 April 2015/Accepted: 6 June 2015/Published online: 2 July 2015

(C) Springer Science+Business Media New York 2015

\begin{abstract}
The high use of pesticides in intensive rice farming in the Mekong Delta constitutes a potential hazard to the environment and to people's health. Chlorpyrifos ethyl (CPF) is a commonly used organophosphate (OP) insecticide, but information about its potential negative impacts on the aquatic environment in the Mekong Delta is scarce. Both acute and subacute toxicity tests were performed in a static nonrenewable system to investigate the effects of CPF on brain acetylcholinesterase (AChE) activity in native climbing perch fingerlings (Anabas testudineus, Bloch, 1972). Environmental parameters, such as dissolved oxygen, water temperature, and $\mathrm{pH}$, were similar to field conditions in the Mekong Delta. In a 96-h lethal concentration $\left(\mathrm{LC}_{50}\right)$ test, fingerlings of climbing perch were randomly exposed to five levels of CPF ranging from 0.8 to $4.5 \mathrm{ppm}$. Five sublethal levels of CPF $(1,5,10,15$, and $20 \%$ of the $96-\mathrm{h} \mathrm{LC}_{50}$ value) were tested to assess the sensitivity and recovery of the brain AChE activity in climbing perch fingerlings exposed to CPF. The results showed that $\mathrm{CPF}$ were moderately toxic to climbing perch with a 96-h median $\mathrm{LC}_{50}$ of $1.73 \mathrm{ppm}$. CPF also caused long-term AChE inhibition with $70 \%$ inhibition remaining after $96 \mathrm{~h}$ for the four highest test concentrations. The recovery of brain AChE activity in fish placed in CPF-free water was very slow, and after 7 days the brain $\mathrm{AChE}$
\end{abstract}

Nguyen Thanh Tam

thanhtamts25@gmail.com; tam@ecology.su.se

1 Faculty of Fisheries, Nong Lam University, Ho Chi Minh City, Vietnam

2 College of Environment and Natural Resources, Can Tho University, 3/2 Street, Can Tho City, Vietnam

3 Department of Physical Geography, Stockholm University, SE-106 91 Stockholm, Sweden activity was still significant lower in fish from the four highest concentrations compared with the control. The results from this study indicate that $\mathrm{OP}$ insecticides, such as $\mathrm{CPF}$, can have long-lasting sublethal effects on aquatic species in the Mekong Delta.

The Mekong Delta occupies approximately $12 \%$ of Vietnam's total area, but it contributes $>50 \%$ of the total national rice production (Renaud and Kuenzer 2012). Since the 1980 s, there has been a steady increase in the production of rice, through increased areas of rice farming and application of more intensive farming methods, supported by a high use of agrochemicals (Renaud and Kuenzer 2012). Many farmers currently apply three crops per year, with a high use of both fertilisers and pesticides, to meet the expected increase in future rice yields (Cau 2011; Guong and Hoa 2012). Pesticide imports to Vietnam increased from 20,000 to 72,560 tons during the period 1991-2010 with a corresponding increase in number of active ingredients (a.i.) applied from 77 to 300 during the same period of time (Toan et al. 2013). The increased use of pesticides has been followed by an increased risk for negative effects on the environment and on people's health (Berg et al. 2012; Dasgupta et al. 2007; Sebesvari et al. 2012).

Chlorpyrifos ethyl (CPF) is a commonly used organophosphate (OP) insecticide in the Mekong Delta (Heong et al. 1998; Huan et al. 1999; Phong et al. 2010). Although OPs have a lower tendency to bioaccumulate in aquatic organisms compared with many organochlorines, they are often more toxic to aquatic organisms (Tilak et al. 2001). CPF is known to be highly toxic to freshwater fish and aquatic invertebrates because of its ability to inhibit the acetylcholinesterase (AChE) enzyme and cause 
malformation of the nervous system (O'Brien 1976; Peakall 1992). According to Peakall (1992), the inhibition of AChE results in abnormal respiration, swimming, feeding, and social interactions in aquatic organisms due to loss of coordination, tremors, muscle spasms, convulsions, and even death.

As shown by several studies, the sensitivity of brain AChE activity to different inhibitors can be used as a biomarker to indicate the degree of sublethal effects from $\mathrm{OP}$ and carbamate insecticides on aquatic organisms (Coppage et al. 1975; Sancho et al. 2000). However, as pointed out by Chuiko et al. (2003), the AChE response to different inhibitors varies substantially between different fish species. Considering the high use of both OPs and carbamates in the Mekong Delta, there is a need to provide more information on the response of the AChE activity in local fish species exposed to these pesticides in rice fields in the Mekong Delta. This is an important step to develop locally relevant biomarkers that can be used to identify long-lasting sublethal effects from pesticides on aquatic organisms under tropical conditions.

In this study, climbing perch (Anabas testudineus) was selected as a model organism because it is a native fish commonly found in rice fields, where it lives and reproduces, and thus is exposed to agrochemicals during all of its life stages (Rainboth 1996). In addition, it is an important food fish that is considered to be of high quality, thus contributing to local people's livelihoods and wellbeing in the Mekong Delta (Edwards et al. 1997; Herre 1952; Klemick and Lichtenberg 2008). Climbing perch has also been shown to be an important predator of rice pests, such as brown plant hoppers [Nilaparvata lugens (Stål)], and could potentially help to reduce the use of insecticides to control these pests (Nam et al. 2012).

Although there are no official reports about the status of climbing perch populations in the Mekong Delta, local farmers indicate that the amount of wild fish in rice fields has decreased during the last decades (Edwards et al. 1997). Acute and chronic toxicities of several pesticides have been investigated in climbing perch (Binoy et al. 2004; Choudhury et al. 1993; Cong and Linh 2010; Jilna and John 2011), but information regarding the effects of $\mathrm{CPF}$ is scarce. No information is available on the inhibition of AChE by CPF in climbing perch.

The aim of the present study was to investigate the effects on brain AChE activity in climbing perch fingerlings exposed to sublethal concentrations of CPF that were similar to the concentrations found in rice fields in the Mekong Delta. The study thus provides a basis for evaluating sublethal effects on fish by OP insecticides used in rice farming and for developing locally relevant and feasible biomarkers for the monitoring of sublethal effects by pesticides on fish from the Mekong Delta.

\section{Materials and Methods}

\section{Fish}

Climbing perch fingerlings $(3-4 \mathrm{~g})$ were bought from a hatchery in Co Do district, Can Tho city, Vietnam. The fingerlings were produced by a brood-stock caught from an area with no use of pesticides in the Mekong Delta to ensure that the fingerlings were not affected by any previous exposure of pesticides to the brood-stock. The fingerlings were acclimatized in a 600-L fiberglass tank for approximately 3 weeks. The fingerlings were fed red worms (Tubifex sp.) daily at approximately $5 \%$ of the total fish fresh weight. The fiberglass tank was cleaned daily before feeding and again $4 \mathrm{~h}$ after feeding. To remove uneaten food and faeces, approximately $50 \%$ of the water was changed on a daily basis. Feeding was stopped 1 day before the experiment was initiated.

\section{Insecticides}

Vitashield 40EC, an OP insecticide (containing $40 \% \mathrm{CPF}$ $[O, O$-diethyl $O$-(3, 5,6-trichloro-2-pyrinidyl)-phosphorothioate; common name "chlorpyrifos"; inert ingredients including emulsifiers and solvents $\leq 100 \%$ ) was purchased from Thanh Son Hoa Nong Company (Binh Chanh district, Ho Chi Minh city, Vietnam).

\section{Experimental Design}

\section{Ninety-Six-Hour $L_{50}$ Toxicity Test}

A toxicity range-finding experiment was performed to determine a CPF concentration that would kill 10-90\% of the climbing perch fingerlings in $96 \mathrm{~h}$. The experiment was performed in 50-L fiberglass tanks containing $20 \mathrm{~L}$ of tap water with three simultaneous replicates of nine treatments containing $0.5,1,1.5,2,2.5,3,3.5,4$, and $4.5 \mathrm{ppm}$ of CPF. The commercial product (Vitashield 40EC, Thanh Son Hoa Nong Company, Vietnam) was diluted 500 times with distilled water to achieve the stock solution with the nominal concentration of $800 \mathrm{ppm}$ of $\mathrm{CPF}$, which is equivalent to $2000 \mathrm{ppm}$ of Vitashield 40EC (Thanh Son Hoa Nong Company, Vietnam).

The accuracy of the nominal concentration was checked with gas chromatography, and the final CPF concentration of the stock solution was determined to $760 \mathrm{ppm}$. The stock solution was then added to the nine treatments to obtain the desired concentrations.

Within 5 min after preparing the different concentrations, 10 fish were randomly removed from the fiberglass stocking tank and added to each experimental tank. There were no feeding and water exchange during the experiment. Dead fish were removed from the tanks to minimize 
any interference with the live fish. Mortality was recorded at 1, 3, 6, 9, 12, 24, 36, 48, 60, 72, 84, and $96 \mathrm{~h}$. Dissolved oxygen (DO), $\mathrm{pH}$, and temperature were measured daily in the morning (6:00-7:00 am) and in the afternoon (14:00-15:00 pm) using a pH meter (HANNA HI8314, Hanna Instruments, USA) and a DO meter (HANNA HI9146, Hanna Instruments, USA) throughout the experiment.

Based on the toxicity range-finding experiment, a 96-h $\mathrm{LC}_{50}$ acute toxicity test was performed. The test was performed in 50-L fiberglass tanks containing $20 \mathrm{~L}$ of tap water (static nonrenewable) that had been aerated overnight. The experiment was performed with three simultaneous replicates of five treatments containing $0.8,1.2,1.9$, 2.9 , and $4.5 \mathrm{ppm}$ of CPF and a control. The treatment concentrations were prepared as mentioned previously. Each replicate contained 10 fish that had been randomly taken from the fiberglass stocking tank and added to the different concentrations. The experiment tanks were regularly monitored during the whole experiment (96 h). Dead fish were removed from the tanks. Mortality was recorded at $1,3,6,9,12,24,36,48,60,72,84$, and 96 h. DO, pH, and temperature were measured daily in the morning $(6: 00-7: 00 \mathrm{am})$ and in the afternoon (14:00-15:00 pm) using a pH meter (HANNA HI8314, Hanna Instruments, USA) and a DO meter (HANNA HI9146, Hanna Instruments, USA) throughout the experiment.

\section{AChE Sensitivity and Recovery Tests}

The AChE sensitivity test was performed using 50-L fiberglass tanks containing $40 \mathrm{~L}$ of tap water that had been aerated overnight to eliminate residues of chlorine in the water. The experiment was performed with three simultaneous replicates including a control and five concentrations of $\mathrm{CPF}$ corresponding to $1,5,10,15$ and $20 \%$ of the identified 96-h $\mathrm{LC}_{50}$ concentration, which is equivalent to $17.3,86.5,173$, 259.5, and $346 \mathrm{ppb}$ of CPF. The treatment concentrations were prepared as mentioned previously. Each replicate contained 30 fish, which were randomly removed from the stocking tank. During the experiment ( $96 \mathrm{~h})$, there was no feeding, aeration or water exchange. $\mathrm{DO}, \mathrm{pH}$, and temperature were measured daily at 6:00-7.00 am and at 14:00-15:00 pm. Two fish were removed after 1, 6, 12, 24, 48, 72, and $96 \mathrm{~h}$ from each experimental tank, killed on ice, and processed for AChE analysis within $12 \mathrm{~h}$.

The recovery test was initiated after $96 \mathrm{~h}$ by replacing all of the water in the experimental tanks with CPF-free water. Afterward, $50 \%$ of the water was replaced on a daily basis. $\mathrm{DO}, \mathrm{pH}$, and temperature were measured daily at 6:00-7.00 am and at 14:00-15:00 pm. To avoid any harmful build up of uneaten food during the experiment, the fish were fed Tubifex worms two times per day at approximately $5 \%$ of the fish fresh weight. After $3 \mathrm{~h}$, the remaining food in each tank was siphoned out into glass containers using a separate system for each treatment concentration. The siphoned water was allowed to settle for $30 \mathrm{~min}$ before the supernatant was returned to the same fiberglass tank. At days 1, 3, 5 and 7, two fish were randomly caught from each tank, immediately killed on ice, and processed for AChE analysis.

\section{AChE Assay}

The brain was dissected out on ice and placed in a preweighted Eppendorf tube on ice before measurement of the brain weight. Each brain was then homogenized on ice in $6 \mathrm{~mL}$ of $0.1 \mathrm{M}$ phosphate buffer ( $\mathrm{pH} 7.4$, prepared by mixing mono and dibasic sodium hydrogen phosphate) using a glass homogenizer. The homogenates were transferred into $10-\mathrm{mL}$ glass tubes and centrifuged at $2000 \times g$ at $4{ }^{\circ} \mathrm{C}$ for $20 \mathrm{~min}$ (Centrifuge 4k15; Sigma, Osterode am Harz, Germany). Supernatant, $1.5 \mathrm{~mL}$, was removed to an Eppendorf tube and kept on ice for AChE analysis within $12 \mathrm{~h}$. The AChE activity was determined according to the method described by Ellman et al. (1961). All measurements were performed in an air-conditioned room at $25{ }^{\circ} \mathrm{C}$. For each measurement, a cuvette was prepared containing $2.65 \mathrm{~mL}$ of $0.1 \mathrm{M}$ phosphate buffer (pH 7.4) and $100 \mu \mathrm{L}$ of 3 mM 5.5 dithio-bis (2nitrobenzoic acid) (Sigma Aldrich Chemie, Steinheim, Germany). Immediately before measurements, $50 \mu \mathrm{L}$ of $10 \mathrm{mM}$ acetylthiocholine iodide (Sigma Aldrich Chemie, Steinheim, Germany) and $200 \mu \mathrm{L}$ of supernatant were added, and the solution was mixed well. Blanks were prepared with $200 \mu \mathrm{L}$ of buffer instead of the supernatant. Two blanks were used for each sample measurement. AChE enzyme activity was measured using an ultraviolet/visible spectrophotometer (model UV2 2000E; ATI Unicam, Cambridge, UK) for 10 cycles ( $3 \mathrm{~min}$ and $18 \mathrm{~s}$ ) with an auto interval (22 s) at a wavelength of $412 \mathrm{~nm}$ when the increase in absorbance with time was linear. The results of these measurements were expressed as a rate (absorbance per minute), from which the AChE activity was calculated.

\section{Statistical Analysis}

The 96-h $\mathrm{LC}_{50}$ value for $\mathrm{CPF}$ was calculated by probit analysis (Finney 1971) using the probit function in SPSS for Windows (SPSS Inc, Chicago, IL, USA). Differences in AChE activity between treatments were analyzed using one-way analysis of variance with Dunnett's test for post hoc comparisons after checking for normality and homogeneity of variance. SPSS for windows (version 17.0, SPSS Inc, Chicago, IL, USA) was used to analyse the data. 


\section{Results}

\section{Ninety-Six-Hour LC $_{50}$ Toxicity Test}

$\mathrm{DO}, \mathrm{pH}$, and temperature during the acute toxicity test were similar to the field conditions in rice fields in the Mekong Delta. The temperature varied between 24.2 and $24.4^{\circ} \mathrm{C}$. The $\mathrm{pH}$ was stable throughout the experiment ranging from 6.7 to 6.9 (Table 1). There were no significant differences in $\mathrm{pH}$ and temperature between the different treatments at any sampling time. However, the DO level in the control was $3.5 \mathrm{mg} / \mathrm{L}$, which was significant higher than the DO levels in the different treatments $(P<0.05)$. The DO level in the treatment containing $0.8 \mathrm{mg} \mathrm{CPF} / \mathrm{L}$ was significant lower compared with the control, but it was significant higher compared with the other treatments $(P<0.05)$ (Table 1$)$.

Nine hours after the experiment was initiated, fish mortalities were recorded in the two highest concentrations (4.5 and $2.9 \mathrm{ppm}$ ) (Table 2). In the following two lower concentrations (1.9 and $1.2 \mathrm{ppm}$ ), the first fish died after $12 \mathrm{~h}$. In the lowest concentration $(0.8 \mathrm{ppm})$, the first fish died after $60 \mathrm{~h}$. By this time, the majority of the fish in the two highest concentrations had died. At the end of the experiment, only one fish had died in the control, whereas $<50 \%$ of the fish in the lower concentrations and approximately $90 \%$ of the fish in the highest concentrations had died. The 24-, 36-, 48-, 60-, 72-, 84-, and 96-h $\mathrm{LC}_{50}$ values of $\mathrm{CPF}$ for climbing perch fingerlings were determined to $2.5,2.2,2.0,1.91,1.82,1.78$, and $1.73 \mathrm{ppm}$, respectively (Table 2).

\section{AChE Sensitivity Test}

The temperatures varied between 26.7 and $26.8{ }^{\circ} \mathrm{C}$, and the $\mathrm{pH}$ ranged between 6.9 and 7.0 during the experiment (Table 3). There were no significant differences in $\mathrm{pH}$ and temperature between the different treatments at any sampling time. However, with increasing CPF concentrations, the DO levels were significantly reduced $(P<0.05)$. The highest DO level was found in the control, and the lowest DO level was found in the treatment containing the highest concentration of $\mathrm{CPF}$ (346 $\mu \mathrm{g} \mathrm{CPF/L)} \mathrm{(Table} \mathrm{3).}$

There was a clear correlation between the CPF dose and inhibition of brain AChE activity. After $1 \mathrm{~h}$, no signs of inhibition were observed in fish exposed to 1 and $5 \%$ of the 96-h $\mathrm{LC}_{50}$ concentration (Fig. 1). The brain AChE activities in the fish from these treatments were even higher than those in the fish from the control treatment $(P<0.05)$. However, the fish exposed to 10,15 , and $20 \%$ of the 96-h $\mathrm{LC}_{50}$ concentration showed brain AChE inhibition of 15.6, 8.2, and $17.7 \%$, respectively (Fig. 1). After $6 \mathrm{~h}$, brain AChE activities had decreased in all treatments, and the inhibition levels ranged between 20 and $50 \%$, with the highest reduction in fish exposed the highest concentration. After $48 \mathrm{~h}$, the inhibition peaked, with inhibition levels $>50 \%$ for all treatments and $>75 \%$ for the three highest concentrations. At the end of experiment $(96 \mathrm{~h})$, the inhibition levels of the fish exposed to $1,5,10,15$, and $20 \%$ of the $96-\mathrm{h} \mathrm{LC}_{50}$ concentration were $34.6,43.5,67,64.1$, and $69.8 \%$, respectively (Fig. 1). There were no clear signs of recovery among the exposed fish.

\section{AChE Recovery Test}

Temperature, DO, and $\mathrm{pH}$ were relatively constant during the experiment. The temperature varied between 27.4 and $27.6{ }^{\circ} \mathrm{C}$, and DO levels varied between 2.5 and $2.7 \mathrm{mg} / \mathrm{L}$. $\mathrm{pH}$ varied between 7.1 and 7.2 (Table 4). No significant differences were found between treatments at any time $(P>0.05)$.

One day after the removal of the water containing CPF, brain AChE levels had decreased to 23, 43, 52, 54, and $57 \%$ for fish exposed to $1,5,10,15$, and $20 \%$ of the $96-\mathrm{h} \mathrm{LC}_{50}$ concentration, respectively (Fig. 2). At day 3, inhibition levels had decreased to $19,34,44,50$, and $53 \%$, but they were still significant higher than that of the control $(P<0.05)$. The fish exposed to the lowest concentration recovered fully after 5 days, whereas the inhibition levels in fish exposed to the higher concentrations remained significantly higher than the control after 7 days $(P<0.05)$ (Fig. 2).
Table 1 Water parameters in static $96-\mathrm{LC}_{50}$ test on climbing perch fingerlings exposed to $\mathrm{CPF}$

\begin{tabular}{lcccccr}
\hline CPF (ppm) & \multicolumn{1}{l}{0} & \multicolumn{1}{l}{0.8} & \multicolumn{1}{l}{1.2} & \multicolumn{1}{l}{1.9} & \multicolumn{1}{l}{2.9} & \multicolumn{1}{c}{4.5} \\
\hline $\mathrm{T}\left({ }^{\circ} \mathrm{C}\right)$ & $24.4 \pm 0.05$ & $24.3 \pm 0.04$ & $24.3 \pm 0.04$ & $24.3 \pm 0.02$ & $24.2 \pm 0.04$ & $24.2 \pm 0.05$ \\
$\mathrm{pH}$ & $6.9 \pm 0.07$ & $6.8 \pm 0.05$ & $6.7 \pm 0.05$ & $6.7 \pm 0.04$ & $6.7 \pm 0.04$ & $6.8 \pm 0.04$ \\
$\mathrm{DO}(\mathrm{mg} / \mathrm{L})$ & $3.5 \pm 0.10^{\mathrm{a}}$ & $2.4 \pm 0.20^{\mathrm{b}}$ & $2.2 \pm 0.17^{\mathrm{bc}}$ & $1.7 \pm 0.20^{\mathrm{c}}$ & $1.7 \pm 0.20^{\mathrm{c}}$ & $1.8 \pm 0.18^{\mathrm{c}}$ \\
\hline
\end{tabular}

Data are expressed as mean \pm SE of triplicate measurements. Values having different superscripts within the same row are significantly different $(P<0.05)$ 
Table 2 Cumulative mortality (\% of dead fish) of climbing perch fingerling exposed to $\mathrm{CPF}$

Table 3 Water parameters in AChE sensitivity test on climbing perch fingerlings exposed to $\mathrm{CPF}$

\begin{tabular}{|c|c|c|c|c|c|c|c|}
\hline \multirow[t]{2}{*}{ Time (h) } & \multicolumn{6}{|c|}{$\mathrm{CPF}(\mathrm{ppm})$} & \multirow[t]{2}{*}{$\mathrm{LC}_{50}(\mathrm{ppm})$} \\
\hline & Control & 0.8 & 1.2 & 1.9 & 2.9 & 4.5 & \\
\hline 0 & 0 & 0 & 0 & 0 & 0 & 0 & \\
\hline 6 & 0 & 0 & 0 & 0 & 0 & 0 & \\
\hline 9 & 0 & 0 & 0 & 0 & 6.67 & 16.67 & \\
\hline 12 & 0 & 0 & 6.67 & 10.00 & 36.67 & 40.00 & \\
\hline 24 & 0 & 0 & 13.33 & 20.00 & 63.33 & 70.00 & 2.50 \\
\hline 36 & 0 & 0 & 16.67 & 30.00 & 63.33 & 80.00 & 2.20 \\
\hline 48 & 0 & 0 & 26.67 & 33.33 & 70.00 & 80.00 & 2.00 \\
\hline 60 & 0 & 10.00 & 26.67 & 36.67 & 73.33 & 83.33 & 1.91 \\
\hline 72 & 0 & 10.00 & 26.67 & 46.67 & 76.67 & 86.67 & 1.82 \\
\hline 84 & 0 & 13.33 & 33.33 & 50.00 & 76.67 & 86.67 & 1.78 \\
\hline 96 & 3.33 & 13.33 & 33.33 & 50.00 & 86.67 & 90.00 & 1.73 \\
\hline
\end{tabular}

\begin{tabular}{lcccccr}
\hline $\mathrm{CPF}(\mathrm{ppb})$ & 0 & 17.3 & 86.5 & 173 & 259.5 & \multicolumn{1}{c}{346} \\
\hline $\mathrm{T}\left({ }^{\circ} \mathrm{C}\right)$ & $26.8 \pm 0.32$ & $26.7 \pm 0.29$ & $26.7 \pm 0.30$ & $26.7 \pm 0.30$ & $26.7 \pm 0.29$ & $26.7 \pm 0.31$ \\
$\mathrm{pH}$ & $6.9 \pm 0.05$ & $6.9 \pm 0.05$ & $6.9 \pm 0.03$ & $7.0 \pm 0.01$ & $7.0 \pm 0.01$ & $7.0 \pm 0.01$ \\
$\mathrm{DO}(\mathrm{mg} / \mathrm{L})$ & $2.7 \pm 0.05^{\mathrm{a}}$ & $2.4 \pm 0.06^{\mathrm{b}}$ & $2.4 \pm 0.06^{\mathrm{b}}$ & $2.24 \pm 0.06^{\mathrm{b}}$ & $1.77 \pm 0.10^{\mathrm{c}}$ & $1.44 \pm 0.15^{\mathrm{d}}$
\end{tabular}

Data are expressed as mean \pm SE of triplicate measurements. Values having different superscripts within the same row are significantly different $(P<0.05)$

Fig. 1 Brain acetylcholinesterase (AChE) inhibition in climbing perch (Anabas testudineus) fingerlings exposed to chlorpyrifos ethyl (Vitashield 40EC, Thanh Son Hoa Nong Company, Vietnam) during $96 \mathrm{~h}$ at concentrations of $1,5,10,15$ and $20 \%$ of the $96 \mathrm{~h}$ LC50 value for chlorpyrifos ethyl. The vertical bars show standard error. Points with different letters are significantly different $(P<0.05)$ from each other. Each data point corresponds to the mean of six samples

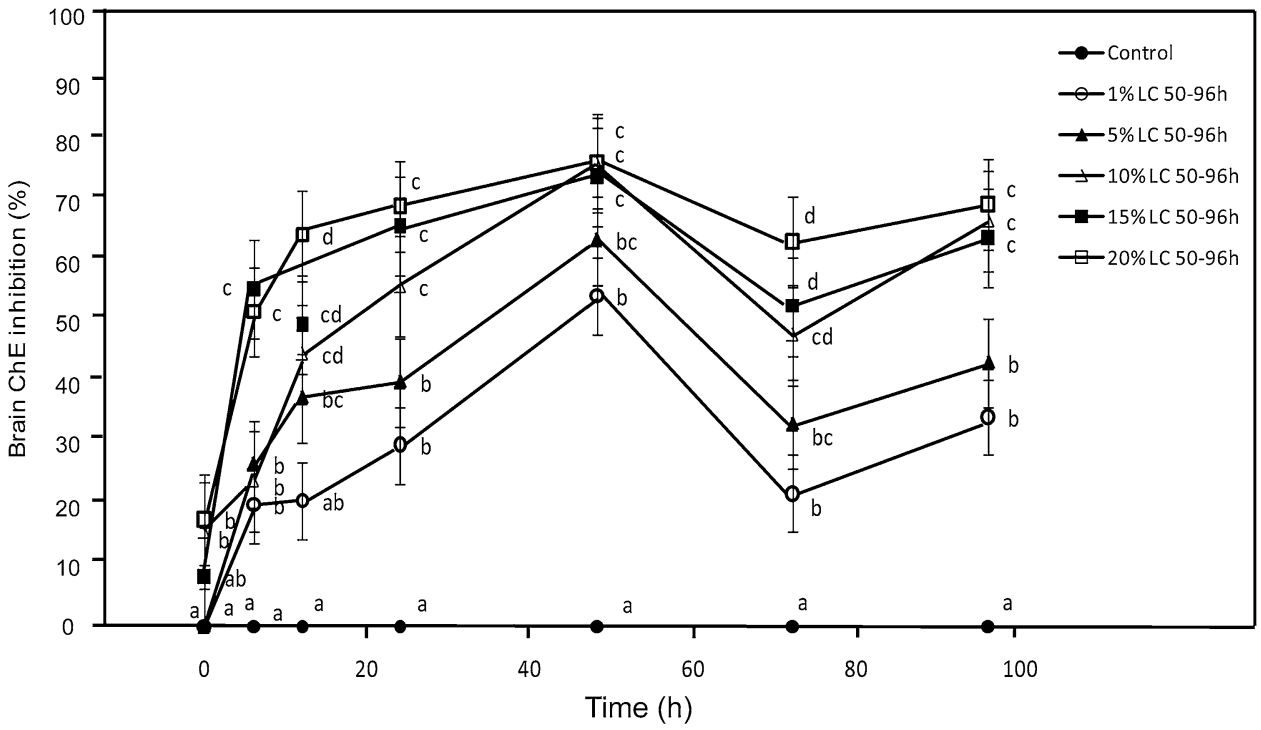

\begin{tabular}{lcrrrrr}
\hline CPF $(\mathrm{ppb})$ & \multicolumn{1}{l}{0} & \multicolumn{1}{c}{17.3} & \multicolumn{1}{c}{86.5} & \multicolumn{1}{c}{173} & \multicolumn{1}{c}{259.5} & \multicolumn{1}{c}{346} \\
\hline $\mathrm{T}\left({ }^{\circ} \mathrm{C}\right)$ & $27.6 \pm 0.22$ & $27.5 \pm 0.22$ & $27.4 \pm 0.22$ & $27.4 \pm 0.22$ & $27.4 \pm 0.22$ & $27.4 \pm 0.22$ \\
$\mathrm{pH}$ & $7.2 \pm 0.1$ & $7.1 \pm 0.01$ & $7.2 \pm 0.01$ & $7.1 \pm 0.02$ & $7.1 \pm 0.01$ & $7.2 \pm 0.01$ \\
$\mathrm{DO}(\mathrm{mg} / \mathrm{L})$ & $2.7 \pm 0.07$ & $2.6 \pm 0.06$ & $2.7 \pm 0.06$ & $2.5 \pm 0.06$ & $2.5 \pm 0.06$ & $2.5 \pm 0.06$
\end{tabular}

Data are expressed as mean \pm SE of triplicate measurements. Values having different superscripts within the same row are significantly different $(P<0.05)$
Table 4 Water parameters in $\mathrm{AChE}$ recovery test on climbing perch fingerlings exposed to $\mathrm{CPF}$ 
Fig. 2 Recovery from brain acetylcholinesterase (AChE) inhibition in climbing perch (Anabas testudineus) fingerlings exposed to different concentrations of chlorpyrifos ethyl for $96 \mathrm{~h}$ followed by 7 days recovery in chlorpyrifos ethyl free-water. The vertical bars show standard error. Points with different letters are significantly different $(P<0.05)$ from each other. Each data point corresponds to the mean of six samples

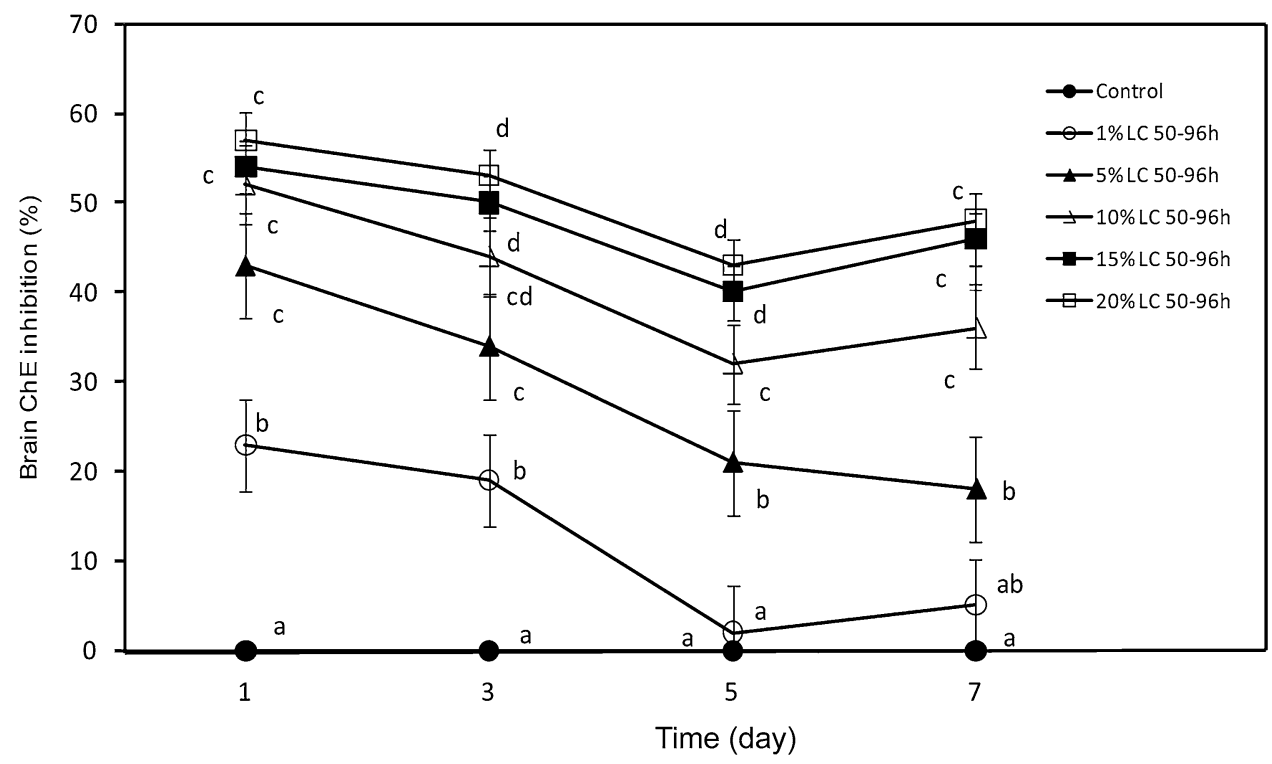

\section{Discussion}

In the Mekong Delta, rice fields are natural and important habitats for climbing perch, and this fish species is directly exposed to pesticide levels that can cause sublethal effects during all of its life stages (Stadlinger et al. 2015; Tam et al. 2015). Although no population survey on climbing perch has been published from the Mekong Delta, the perception among local people is that climbing perch population have undergone a decline during the last 25 years (Edwards et al. 1997; Klemick and Lichtenberg 2008), which partly could be due to the increased use of pesticides in the Delta. Climbing perch is a supplementary source of food and income for many households in the Mekong Delta, and declining yields of this species affect local people's livelihoods and well-being.

In this study, we found that $\mathrm{CPF}$ is moderately toxic to climbing perch $\left(1<\mathrm{LC}_{50}<10 \mathrm{mg} / \mathrm{L}\right)$ with a $96-\mathrm{h} \mathrm{LC}_{50}$ value of $1.7 \mathrm{mg} / \mathrm{L}$. This indicate that $\mathrm{CPF}$ is more acute toxic to climbing perch than diazinon and fenobucarb, two other commonly used insecticides in the Mekong Delta, where the 96-h $\mathrm{LC}_{50}$ has been reported to be $6.55 \mathrm{mg} / \mathrm{L}$ (Cong et al. 2008b) and $11.37 \mathrm{mg} / \mathrm{L}$ (Lan 2004), respectively.

Climbing perch seems to be more tolerant to $\mathrm{CPF}$ than many other freshwater fish. The 96-h $\mathrm{LC}_{50}$ values of $\mathrm{CPF}$ for juvenile and adult nile tilapia (Tilapia niloticus), common carp (Cyprinus carpio), mosquito fish (Gambusia affinis), and guppy (Poecilia reticulata) were 98.7 and 154.0 (Oruç 2010), 580 (Xing et al. 2012), 297 (Kavitha and Rao 2008), and $175.8 \mu \mathrm{g} / \mathrm{L}$ (Sharbidre et al. 2011), respectively.
The comparatively high $96-\mathrm{h} \mathrm{LC}_{50}$ values of $\mathrm{CPF}$ found in this study could be due to some losses of CPF in the water through dissipation to the air or hydrolysis. The fairly high temperature $\left(24^{\circ} \mathrm{C}\right)$ probably had a positive influence on both the evaporation and hydrolysis processes, whereas the slightly acid water ( $\mathrm{pH}$ 6.8) may have had a negative influence on the hydrolysis of CPF (Christensen et al. 2009). CPF's $\log K_{\text {ow }}$ (4.7) (Smith 1981) and $K_{\text {oc values }}$ (7000-25,000 mL/g) (Racke 1992) also indicate that some CPF may have been adsorbed to the experimental tanks.

Climbing perch has a good ability to adapt to harsh environmental conditions, and the temperature, $\mathrm{pH}$ and $\mathrm{DO}$ levels recorded during the experiments were well within the range of field conditions reported for climbing perch in the delta (Albert 1914; Vromant et al. 2001a, b). Climbing perch is an obligate air-breathing species. Obligate airbreathing fish must breathe air periodically even if the DO levels in water are high; otherwise, they will suffocate. The ability to use oxygen directly from the atmosphere makes climbing perch less sensitive to low oxygen levels in water, and the low levels of DO during the experiments were not seen to affect the survival of the fish (Armbruster 1998). Many studies have shown that climbing perch can tolerate and adapt to extremely harsh environments such as low $\mathrm{pH}$ values, high temperatures, and especially low DO concentrations (Davenport and Abdulmatin 1990; Khoa and Huong 1993; Klepper et al. 1992).

The exposure to CPF resulted in significant inhibition of brain AChE activity in climbing perch for all tested concentrations, indicating that $\mathrm{CPF}$ causes significant sublethal effects in climbing perch at doses well below the 96-h $\mathrm{LC}_{50}$ value. The lower oxygen levels in treatments with high 
CPF concentrations also indicated that the fish were stressed by the exposure to CPF and used an increased amount of energy (increased respiration) to counteract the negative effects from CPF. This results in less energy for growth, and reduced growth has been proposed to be a sensitive measure of chronic toxicity to CPF (Arunachalam et al. 1980; Arunachalam and Palanichamy 1982). Reduced growth was also found in a recent study on climbing perch exposed to CPF in rice fields in the Mekong Delta (Tam et al. 2015). Hegazi et al. (1898) found that sublethal concentrations of CPF not only inhibited brain AChE activity in Clarias lazera but also reduced muscle and liver glycogen and blood glucose levels.

Brain AChE activity was clearly influenced by the concentration and duration of the exposure to CPF. Levels of brain AChE inhibition increased rapidly during the first $48 \mathrm{~h}$ of exposure. Then the inhibition levels were slightly reduced, but they were still significant higher than those of the control. The reduced inhibition indicates an increase in protein synthesis by the fish to compensate for the blocked AChE enzymes by CPF (Gill et al. 1990; Ram et al. 2003).

The inhibition levels of all concentrations, except $1 \%$ of the 96-h $\mathrm{LC}_{50}$ value, remained $>30 \%$ for most of the experiment period. Aprea et al. (2002) noted that inhibition levels $>30 \%$ of brain AChE activity affected the normal behaviour of the fish and that death occurred at inhibition levels $>70 \%$ (Aprea et al. 2002; Fulton and Key 2001). Fish exposed to the three highest concentrations (10-20\% of the 96-h $\mathrm{LC}_{50}$ value) reached $>70 \% \mathrm{AChE}$ inhibition after $48 \mathrm{~h}$, but no dead fish was recorded for these treatments, indicating a high tolerance by climbing perch. Several studies indicates that air-breathing fish increased their oxygen uptake from the atmosphere and reduced the uptake of DO from the water when exposed to pesticides (Cong et al. 2011; Natarajan 1981; Saligo and Trijasse 1998; Toan 2009). This could be a strategy for airbreathing fish, such as climbing perch, to reduce the uptake and toxic effects from pesticides in the water (Affonso and Rantin 2005; Armbruster 1998; Cong et al. 2011).

According to the pesticide label of the manufacturer, the highest recommended dose of Vitashield $40 \mathrm{EC}$ is $0.8 \mathrm{~L} / \mathrm{ha}$. With a water level in the rice field of $20 \mathrm{~cm}$ and assuming that $50 \%$ (Cong et al. 2006) of the sprayed insecticide reaches the water, the concentration of CPF in water would be approximately $80 \mu \mathrm{g} / \mathrm{L}$. This concentration is $4.6 \%$ of the $96-\mathrm{h} \mathrm{LC}_{50}$ value. Although this is only a rough estimate of the concentration in water, it still indicates that the recommended dose of Vitashield 40EC (Thanh Son Hoa Nong Company, Vietnam) may not directly kill climbing perch but may cause long-term sublethal effects on the health and normal development of the fish. A recent field study showed that the concentrations of $\mathrm{CPF}$ in rice field water, sprayed with $0.8 \mathrm{~L}$ Vitashield 40EC/ha, decreased quickly during the first day. The concentrations were well below $1 \%$ of the 96-h $\mathrm{LC}_{50}$ values of $\mathrm{CPF}$ for climbing perch fingerlings, but it still resulted in reduced brain AChE activity, growth, and survival in climbing perch (Tam et al. 2015). Increased mortality was only seen several days (days 5-12) after the spraying, indicating that the acute 96-h $\mathrm{LC}_{50}$ test may not fully capture the delayed effect from CPF. Thus, even if $80 \mu \mathrm{g} / \mathrm{L}$ is an overestimate of the expected concentration in water, much lower concentrations of CPF in water are likely to cause negative effects on fish in the rice fields, especially because many of these species are likely to be less tolerant than climbing perch. No dead fish was recorded in the AChE sensitivity experiment, although the concentration ranged between 17 and $346 \mu \mathrm{g} / \mathrm{L}$, which could be due to a more controlled and less stressful environment in the laboratory compared with the rice fields but also because the test period was not long enough to capture the delayed effect caused by CPF.

In addition to the lowered brain AChE activity, increased oxygen consumption, and changed behaviour of the tested fish, such as lowered activity, erratic swimming, and rapid gill movements, also occurred indicating sublethal effects on the fish nervous system. These findings are consistent with those of several other researchers (Bálint et al. 1995; Hai et al. 1997; Levin et al. 2004; Pan and Dutta 1998; Richendrfer et al. 2012; Sancho et al. 2000) who observed changes in feeding capability, swimming activity, avoidance of predators, and spatial orientation due to brain AChE inhibition caused by OP insecticides.

The results from this study also show that the effects from CPF on climbing perch remain many days after the spraying of the pesticide has stopped. This is of a special concern in the Mekong Delta because many farmers in the Delta spray their fields several times per crop and often grow three crops per year (Berg 2001; Berg and Tam 2012). This means that aquatic organisms in the rice fields may continuously be exposed to, and stressed by, elevated levels of pesticides, which are often combined in different mixtures with potential synergistic effects.

Except for the two lowest concentrations (0.0173 and $0.0865 \mathrm{ppm})$, the inhibition of brain AChE activity in climbing perch remained $>30 \%$ after 7 days in CPF-free water. In a previous field study, inhibition of AChE activity remained at 10-20\% in climbing perch fingerlings 12 days after spraying rice fields with $0.8 \mathrm{~L}$ Vitashield 40EC/ha (Tam et al. 2015). In a study on snake-head fish (Channa striata) exposed to diazinon sprayed on rice fields in the Mekong Delta, the brain AChE activity dropped to a minimum value 3 days after spraying and only gradually recovered to $74 \%$ of prespraying activity after 21 days (Cong et al. 2008a).

Rao (2004) found that the activity of brain AChE in Orechromis mossambicus was fully recovered 22 days after exposure to monocrotophos (containing oxon group, 
$\mathrm{P}=\mathrm{O}$ ), whereas it took 36 days to recover from the exposure to OPs containing a thiol group. Although the detoxifying ability depends on the physiochemical properties of the pesticide (De Bruijn et al. 1993) and also differs between fish species (Keizer et al. 1991), it is clear that OPs, like CPF, generate long-term sublethal effects on aquatic organisms. This could have implications for the overall production of fish and other aquatic organisms in rice fields because the use of pesticides may affect the both growth and survival rates of these organisms (Berg et al. 2012; Tam et al. 2015).

\section{Conclusion}

In conclusion, CPF was found to be moderately toxic to climbing perch fingerlings with a 96-h $\mathrm{LC}_{50}$ value of $1.73 \mathrm{ppm}$. The brain AChE activity of climbing perch fingerlings was very sensitive to CPF. At the lowest concentration ( 1 of the \% 96-h LC50 value or $0.0173 \mathrm{ppm}$ CPF), brain AChE activity was inhibited by $54.6 \%$ after $48 \mathrm{~h}$ of exposure. The recovery of brain AChE activity was very slow, and at the termination of the experiment after 7 days, only the fish exposed to the lowest dose (1\% of the 96-h $\mathrm{LC}_{50}$ value) was fully recovered. The results indicate that $\mathrm{CPF}$ concentrations used by rice farmers in the Mekong Delta may cause sublethal effects on the fish nervous system, which in turn could affect fish growth and yield. This should be further investigated through field studies on the effect of rice farmers' application of CPF in combination with other insecticides on climbing perch as well as other organisms in rice fields.

Acknowledgments This study was financially supported by the Swedish International Development Cooperation Agency (Sida) (Reference No. AKT2010-010) through the Partner Driven Cooperation project Managing Ecosystem Services for Sustainable Aquaculture Development. The study was also funded by the Ministry of Education and Training of Vietnam (Reference No. 4069/QĐBGDĐT). The manuscript was improved with the help of two anonymous reviewers.

\section{References}

Affonso EG, Rantin FT (2005) Respiratory responses of the airbreathing fish Hoplosternum littorale to hypoxia and hydrogen sulfide. Comp Biochem Physiol C 141:275-280

Albert K (1914) Notes on the habits, morphology of the reproductive organs, and embryology of the viviparous fish Gambusia affinis. Government Printing Office, Washington, DC

Aprea C, Colosio C, Mammone T, Minoia C, Maroni M (2002) Biological monitoring of pesticide exposure: a review of analytical methods. J Chromatogr B 769:191-219

Armbruster JW (1998) Modifications of the digestive tract for holding air in Loricariid and Scoloplacid catfishes. Copeia 3:663-675
Arunachalam S, Palanichamy S (1982) Sublethal effects of carbaryl on surfacing behavior and food utilization in the air-breathing fish, Macropodus cupanus. Physiol Behav 29:23-27

Arunachalam S, Jeyalakshmi K, Aboobucker S (1980) Toxic and sublethal effects of carbaryl on freshwater catfish, Mystus vittaus (Bloch). Arch Environ Contam Toxicol 9:307-316

Athens GA, Tam NT, Berg H, Cong NV, Hang NTT (2015) Effects of chlorpyrifos ethyl on acetylcholinesterase activity in climbing perch cultured in rice fields in the Mekong Delta, Vietnam. Ecotoxicol Environ Saf 117:34-40

Bálint T, Szegletes T, Szegletes Z, Halasy K, Nemcsók J (1995) Biochemical and subcellular changes in carp exposed to the organophosphorus methidathion and the pyrethroid deltamethrin. Aquat Toxicol 33:279-295

Berg H (2001) Pesticide use in rice and rice-fish farms in the Mekong Delta, Vietnam. Crop Prot 20:897-905

Berg H, Tam NT (2012) Use of pesticides and attitude to pest management strategies among rice and rice-fish farmers in the Mekong Delta, Vietnam. Int J Pest Manag 58:153-164

Berg H, Berg C, Nguyen TT (2012) Integrated rice-fish farming: safeguarding biodiversity and ecosystem services for sustainable food production in the Mekong Delta. J Sustain Agric 36: 859-872

Binoy VV, Nishitha J, Thomas KJ (2004) Influence of dicofol on the behaviour of the climbing perch, Anabas testudineus. Indian $\mathrm{J}$ Fish 51:345-351

Cau QN (2011) Evaluation of rotational rice-fish farming systems and new fish species for concurrent rice-fish culture in the Mekong Delta, Vietnam. Dissertation, Katholieke Universiteit, Leuven, Belgium

Choudhury C, Ray AK, Bhattacharya S, Bhattacharya S (1993) Non lethal concentrations of pesticide impair ovarian function in the freshwater perch, Anabas testudineus. Environ Biol Fish 36:319-324

Christensen K, Harper B, Luukinen B, Buhl K, Stone D (2009) Chlorpyrifos technical fact sheet. National Pesticide Information Center, Oregon State University Extension Services, OR

Chuiko GM, Podgornaya VA, Zhelnin YY (2003) Acetylcholinesterase and butyrylcholinesterase activities in brain and plasma of freshwater teleosts: cross-species and cross-family differences. Comp Biochem Physiol B 135:55-61

Cong NV, Linh NT (2010) The possibility of using muscle cholinesterase in Climbing perch (Anabas estudineus) as biomarker of effects of Diazan 60EC application on rice fields at Binh Thuy district, Can Tho city [in Vietnamese]. Cantho University Press, Cantho City, pp 165-172

Cong NV, Phuong NT, Bayley M (2006) Sensitivity of brain cholinesterase activity to diazinon (BASUDIN 50EC) and fenobucarb (BASSA 50EC) insecticides in the air-breathing fish Channa striata (Bloch, 1793). Environ Toxicol Chem 25:1418-1425

Cong NV, Thanh Phuong N, Bayley M (2008a) Brain cholinesterase response in the snakehead fish (Channa striata) after field exposure to diazinon. Ecotoxicol Environ Saf 71:314-318

Cong NV, Vu NT, Nam TS (2008b) Sensitve of brain cholinesterase to diazinon and fenobucarb in climbing perch (Anabas testudineus, Bloch) fingerling [in Vietnamese]. Cantho University Press, Cantho City 14

Cong NV, Trang NTQ, Nguyen PQ, Thanh VN (2011) Effects of pesticide cypermethrin on mortality, surfacing frequency and growth of fry climbing perch (Anabas testudineus) [in Vietnamese]. Cantho University Press, Cantho City

Coppage DL, Matthews E, Cook GH, Knight J (1975) Brain acetylcholinesterase inhibition in fish as a diagnosis of environmental poisoning by malathion, O,O-dimethyl S-(1,2- 
dicarbethoxyethyl) phosphorodithioate. Pestic Biochem Physiol 5:536-542

Dasgupta S, Meisner C, Wheeler D, Xuyen K, Thi Lam N (2007) Pesticide poisoning of farm workers-implications of blood test results from Vietnam. Int J Hyg Environ Health 210:121-132

Davenport J, Abdulmatin AKM (1990) Terrestrial locomotion in the climbing perch, Anabas-Testudineus (Bloch) (Anabantidea, Pisces). J Fish Biol 37:175-184

De Bruijn J, Seinen W, Hermens J (1993) Biotransformation of organophosphorus compounds by rainbow trout (Oncorhynchus mykiss) liver in relation to bioconcentration. Environ Toxicol Chem 12:1041-1050

Edwards P, Little DC, Yakupitiyage A (1997) A comparison of traditional and modified inland artisanal aquaculture systems. Aquacult Res 28:777-788

Ellman GL, Courtney KD, Andres V Jr, Feather-Stone RM (1961) A new and rapid colorimetric determination of acetylcholinesterase activity. Biochem Pharmacol 7:88-95

Finney DJ (1971) Probit analysis. Volume 60. Journal of pharmaceutical sciences $\left(3^{\text {rd }}\right.$ ed). Volume 9. Wiley subscription services. Cambridge University Press, New York

Fulton MH, Key PB (2001) Acetylcholinesterase inhibition in estuarine fish and invertebrates as an indicator of organophosphorus insecticide exposure and effects. Environ Toxicol Chem 20:37-45

Gill TS, Pande J, Tewari H (1990) Sublethal effects of an organophosphorus insecticide on certain metabolite levels in a freshwater fish, Puntius conchonius hamilton. Peptic Biochem Physiol 36:290-299

Guong V, Hoa N (2012) Aquaculture and agricultural production in the Mekong Delta and its effects on nutrient pollution of soil and water. In: Renaud FG, Kuenzer C (eds) The Mekong Delta system. Springer Environmental Science and Engineering Springer, The Netherlands, pp 363-393

Hai DQ, Varga SI, Matkovics B (1997) Organophosphate effects on antioxidant system of carp (Cyprinus carpio) and catfish (Ictalurus nebulosus). Comp Biochem Physiol C 117:83-88

Hegazi M, El-Shourbagy IK, Abdel-Ghaffar KM (1898) Chronic dursban effects on carbohydrate metabolism in juvenile catfish (Clarias lazera). Delta J Sci 13:510-523

Heong KL, Escalada MM, Huan NH, Mai V (1998) Use of communication media in changing rice farmers' pest management in the Mekong delta, Vietnam. Crop Prot 17:413-425

Herre AW (1952) Philippine fish tales. D. P, Perez

Huan NH, Mai V, Escalada MM, Heong KL (1999) Changes in rice farmers' pest management in the Mekong Delta, Vietnam. Crop Prot 18:557-563

Jilna AN, John TK (2011) Effect of sublethal concentration of methyl parathion on the behavioural activities of the climbing perch (Anabas tesudineus : bloch). Adv Appl Sci Res 2:167-172

Kavitha P, Rao JV (2008) Toxic effects of chlorpyrifos on antioxidant enzymes and target enzyme acetylcholinesterase interaction in mosquito fish, Gambusia affinis. Environ Toxicol Pharmacol 26:192-198

Keizer J, D'Agostino G, Vittozzi L (1991) The importance of biotransformation in the toxicity of xenobiotics to fish. I. Toxicity and bioaccumulation of diazinon in guppy (Poecilia reticulata) and zebra fish (Brachydanio rerio). Aquat Toxicol 21:239-254

Khoa TT, Huong TTT (1993) Freshwater fish species in the Mekong Delta. Cantho University Press, Cantho City

Klemick H, Lichtenberg E (2008) Pesticide use and fish harvests in Vietnamese rice agroecosystems. Am J Agric Econ 90:1-14

Klepper O, Chairuddin GT, Iriansyah H, Rijsken HD (1992) Water quality and the distribution of some fishes in an area of acid sulphate soils, Kalimantan, Indonesia. Hydrobiol Bull $25: 217-224$
Lan TT (2004) Effect of Bassa 50EC on some physiological parameters of climbing perch (Anabas testudineus) [in Vietnamese]. Cantho University Press, Cantho City

Levin ED, Swain HA, Donerly S, Linney E (2004) Developmental chlorpyrifos effects on hatchling zebrafish swimming behavior. Neurotoxicol Teratol 26:719-723

Nam CQ, Vromant N, Tran Thanh B, Ollevier F (2012) Investigation of the predation potential of different fish species on brown planthopper (Nilaparvata lugens (Stål)) in experimental rice-fish aquariums and tanks. Crop Prot 38:95-102

Natarajan GM (1981) Effect of lethal (LC50-48 h) concentration of Metasystox on selected oxidative enzymes, tissue respiration, and histology of gills of the freshwater airbreathing fish, Channa striata (Bleeker). Curr Sci 50:985-989

O'Brien RD (1976) Acetylcholinesterase and its inhibition. In: Wilkinson CF (ed) Insecticide biochemistry and physiology. Springer, New York, pp 271-296

Oruç EÖ (2010) Oxidative stress, steroid hormone concentrations and acetylcholinesterase activity in Oreochromis niloticus exposed to chlorpyrifos. Pestic Biochem Physiol 96:160-166

Pan G, Dutta HM (1998) The inhibition of brain acetylcholinesterase activity of juvenile largemouth bass Micropterus salmoides by sublethal concentrations of diazinon. Environ Res 79:133-137

Peakall DB (1992) Animal biomarkers as pollution indicators. Ecotoxicological series no. 1. Chapman \& Hall, London

Phong LT, van Dam AA, Udo HMJ, van Mensvoort MEF, Tri LQ, Steenstra FA et al (2010) An agro-ecological evaluation of aquaculture integration into farming systems of the Mekong Delta. Agric Ecosyst Environ 138:232-241

Racke KD (1992) The environmental fate of chlorpyrifos. Rev Environ Contam Toxicol 131:1-151

Rainboth WJ (1996) Fishes of the Cambodian Mekong. Food and Agriculture Organization of the United Nations, Rome

Ram PY, Digvijay S, Singh SK, Ajay S (2003) Metabolic changes in freshwater fish Channa punctatus due to Stem-bark extract of Croton tiglium. J Biol Sci 6(14):1223-1228

Rao JV (2004) Effects of monocrotophos and its analogs in acetylcholinesterase activity's inhibition and its pattern of recovery on euryhaline fish, Oreochromis mossambicus. Ecotoxicol Environ Saf 59:217-222

Renaud FG, Kuenzer C (2012) The Mekong Delta system. Interdisciplinary analyses of a River Delta. Springer Environmental Science and Engineering, New York/London

Richendrfer H, Pelkowski SD, Colwill RM, Creton R (2012) Developmental sub-chronic exposure to chlorpyrifos reduces anxiety-related behavior in zebrafish larvae. Neurotoxicol Teratol 34:458-465

Saligo P, Trijasse S (1998) Behavioral responses to Atrazine and diuron in goldfish. Arch Environ Contam Toxicol 35:484-491

Sancho E, Ceron JJ, Ferrando MD (2000) Cholinesterase activity and hematological parameters as biomarkers of sublethal molinate exposure in Anguilla anguilla. Ecotoxicol Environ Saf 46:81-86

Sebesvari Z, Le H, Van Toan P, Arnold U, Renaud F (2012) Agriculture and water quality in the Vietnamese Mekong Delta. In: Renaud FG, Kuenzer C (eds) The Mekong Delta system. Springer Environmental Science and Engineering, Springer, The Netherlands, pp 331-361

Sharbidre AA, Metkari V, Patode P (2011) Effect of methyl parathion and chlorpyrifos on certain biomarkers in various tissues of guppy fish, Poecilia reticulata. Pestic Biochem Physiol 101:132-141

Smith CN (1984) Partition coefficients (log kow) for selected chemicals. In: United States Environmental Protection Agency (ed) User's manual for the pesticide root zone model (PRZM). Release 1. Environmental Research Laboratory, Athens 
Stadlinger N, Berg H, Tam NT, Gunnarsson JS, Van den Brink P (2015) Predicted toxicity risks of pesticides used in paddy rice field in the Mekong and comparison between different agro-Delta, Vietnam, management regimes. SETAC Europe, Barcelona

Tilak KS, Veeraiah K, Ramanakumari GV (2001) Toxicity and effect of chloropyriphos to the freshwater fish Labeo rohita (Hamilton). Neurol Res 20:438-445

Toan NV (2009) Effect of diazinon on the physiological, biochemical and growth of climbing perch (Anabas testudineus). Comp Biochem Physiol A Mol Integr Physiol 153A(2):S142-S143

Toan PV, Sebesvari Z, Blasing M, Rosendahl I, Renaud FG (2013) Pesticide management and their residues in sediments and surface and drinking water in the Mekong Delta, Vietnam. Sci Total Environ 452:28-39
Vromant N, Chau NTH, Ollevier F (2001a) The effect of rice-seeding rate and fish stocking on the floodwater ecology of the trench of a concurrent, direct-seeded rice-fish system. Hydrobiologia 457:105-117

Vromant N, Chau NTH, Ollevier F (2001b) The effect of rice seeding rate and fish stocking on the floodwater ecology of the rice field in direct-seeded, concurrent rice-fish systems. Hydrobiologia 445:151-164

Xing H, Wang X, Sun G, Gao X, Xu S (2012) Effects of atrazine and chlorpyrifos on activity and transcription of glutathione S-transferase in common carp (Cyprinus carpio L.). Environ Toxicol Pharmacol 33:233-244 